\title{
Necessidades formativas dos professores do ciclo I do Ensino Fundamental de Presidente Prudente, SP: uma contribuição para o desenvolvimento profissional do professor Teacher's trainings needs of elementary school in Presidente Prudente, SP: a contribution to the professional development of teacher
}

\author{
Carla Regina Calone Yamashiro* \\ Yoshie Ussami Ferrari Leite**
}

\begin{abstract}
* Professora da Educação Básica da Secretaria de Educação do Estado de São Paulo, no município de Presidente Prudente, SP. E-mail: carlayama@gmail.com

** Professora Adjunta do Departamento de Educação e do Programa de Pós-graduação em Educação da FCT/ UNESP/Campus de Presidente Prudente, SP. E-mail: yoshie@fct.unesp.br
\end{abstract}

\section{Resumo}

Este estudo tem como objeto as necessidades formativas docentes e tem como objetivo investigar as necessidades formativas dos professores estaduais do ciclo I das escolas do município de Presidente Prudente, SP. A pesquisa teve caráter quanti-qualitativo e, como procedimento metodológico, foi aplicado um questionário para setenta e dois professores. Os resultados obtidos foram analisados a partir de autores que discutem o sentido atual da educação escolar, a formação de professores enquanto desenvolvimento profissional e a colaboração da análise de necessidades de formação como diagnóstico para a o planejamento de ações de formação contínua de professores. A pesquisa possibilitou a elaboração de indicadores de necessidades formativas dos professores pesquisados.

\section{Palavras-chave}

Necessidades formativas docentes. Formação e de professores. Função docente.

\begin{abstract}
The subject of this research is the teacher's training needs and its aim is directed to finding out what are the training needs of the teachers of the so-called "ciclo I" (First Stage) of teaching in state schools in the city of Presidente Prudente, São Paulo state. The research was developed through the quantitative-qualitative point of view and the methodological produce used was the application of a questionnaire to seventy two teachers. We were based in autors who discuss themes like the meaning of the school education nowadays, the professional development of teachers and the contribution of the analysis of the teacher's training needs like a diagnosis to plane action to the
\end{abstract}


formation of this professional. The investigation has enabled the definition of indices of the interviewed teacher's training needs.

\section{Key words}

Teacher's training needs. Teacher's formation. Teacher's social role.

\section{Introdução e objetivos}

Pesquisas a propósito das necessidades formativas docentes são uma rara preocupação dos órgãos e instituições responsáveis pela formação de professores, no auxílio ao planejamento de ações destinadas à formação contínua de professores.

Compreendemos, por um lado, que aspectos além da formação técnicopedagógica do professor implicam no seu desenvolvimento profissional, dentre os quais a sua condição sócio-econômica, as suas condições de trabalho, a sua formação profissional e as suas expectativas a respeito da função docente e do papel da educação escolar na sociedade. Por outro lado, entendemos que a participação dos professores nas etapas de planejamento e avaliação dos projetos de formação contínua é de suma importância para que suas necessidades sejam satisfeitas e seu desenvolvimento profissional seja contemplado. No entanto, sabemos que essa participação docente é inexistente, quando não, mínima e limitada. Ao professor, geralmente, resta o papel de executor de tarefas e de atividades, que pouco repercutem no seu desenvolvimento profissional porque são oferecidas sem vínculo com o contexto escolar, em módulos sem continuidade e em horários extraordinários a sua jornada de trabalho.
Dessa forma, a tendência dos órgãos responsáveis pela formação contínua de professores em apresentar modelos prontos - que nem sempre atendem à demanda de necessidades expressas pelos professores - pouco contribui para o desenvolvimento da profissionalidade docente, pois a maioria deles não se direciona pelas necessidades das comunidades e dos professores, mas pelas necessidades do sistema.

Nossa pesquisa, portanto, foi motivada pela problemática do descompasso existente entre as necessidades formativas docentes e os projetos de formação contínua de professores e respondeu ao seguinte questionamento: quais são as necessidades formativas dos professores estaduais de ciclo I do Ensino Fundamental, do município de Presidente Prudente, SP, sendo considerados os seguintes aspectos: as suas condições sócio-econômicas, a sua formação profissional, as suas condições de trabalho e as suas expectativas sobre a função docente e a formação contínua?

Assim, este estudo teve como objetivo geral contribuir com a área de formação contínua de professores, a partir do estudo das necessidades formativas dos professores citados. A partir deste objetivo geral, estabelecemos os três objetivos específicos, quais sejam: investigar as necessidades formativas 
dos professores citados, a partir da caracterização das suas condições socioeconômicas, da sua formação cultural e profissional, das suas condições de trabalho e das suas expectativas sobre a função docente e sobre a formação contínua de professores; analisar as necessidades formativas segundo uma concepção de formação contínua de professores que articula o processo de formação e profissionalização dos docentes no ambiente de trabalho desses profissionais; e, por fim, oferecer indicadores para a planificação de projetos de formação contínua de professores.

Dando sequência a este texto apresentamos os principais referenciais teóricos norteadores da nossa pesquisa, a descrição da sua metodologia e do seu desenvolvimento e, por fim, os seus resultados.

\section{Referencial teórico}

O estudo bibliográfico nos proporcionou condições para construirmos um aporte teórico sobre o sentido social da educação escolar, as especificidades da profissão docente, a perspectiva de formação contínua de professores como desenvolvimento profissional contínuo e o estudo de necessidades formativas no campo da formação de professores, assuntos que nos serviram de referencial para a reflexão dos dados coletados pelo questionário.
2.10 sentido social da educação escolar

A formação de professores está diretamente relacionada ao sentido atribuído à educação escolar e à definição da função do trabalho docente na sociedade, pois os papéis do professor e da escola não estão separados do projeto de sociedade que se vislumbra.

Tedesco (2004) e Singer (1996) concordam a respeito da importância da educação escolar na implementação das bases da sociedade e entendem que a educação escolar é influenciada por diferentes representantes sociais fora da área educacional. Há uma crise na educação escolar cujas causas não residem isoladamente nessa área, mas sim, no conjunto das circunstâncias históricas e sociais associadas ao âmbito econômico e político da sociedade.

De acordo com Tedesco (2004), a crise de identidade da educação escolar resulta do conflito entre quantidade e qualidade de ensino. Depois da necessidade de expandir o ensino, o próximo desafio da educação seria garantir o mesmo grau de equidade qualitativa a todos. No entanto, há fatores de ordem econômica que interferem nas questões educativas. A educação escolar, nesse sentido, pode tornar-se um instrumento de satisfação das necessidades do mercado de trabalho apenas e não um instrumento de satisfação das necessidades sociais das comunidades.

Em concordância com Tedesco (2004), Singer (1996) também ressalta a interdependência entre as questões 
educacionais, políticas e econômicas, defendendo a importância da participação política dos diretamente envolvidos no ensino, ou seja: professores e alunos. Segundo esse autor, o sistema educativo passa por uma crise que tem raízes profundas na alienação dos envolvidos no ensino escolar a respeito "das novas características tanto do mercado de trabalho como do panorama político e social" (SINGER, 1996, p. 12).

A partir desses dois autores, compreendemos que a educação escolar tem encontrado dificuldade de construir e de assumir, por si própria e para si própria, um novo sentido dentro da sociedade atual por causa da restrita preocupação em subsidiar a atitude reflexiva do professor, do aluno e da comunidade dentro das escolas. Ao professor, ainda não foram proporcionados voz nem espaço suficiente para que pudesse interferir nesses projetos em favor de uma ideologia própria, com a finalidade de, assim, dotar de sentido a sua ação pedagógica e, consequentemente, construir a sua identidade profissional frente aos desafios e contradições da sociedade atual. É nesse sentido que defendemos que as ações de formação de professores, tanto inicial como contínua, contemplem a construção constante do sentido da ação desses profissionais para a construção de um projeto social mais favorável aos ideais dos alunos e comunidades para os quais trabalham.
2.2 As especificidades da função docente e o contexto de trabalho do professor: questões a se pensar no delineamento de ações formativas de professores

Entendemos que a articulação da análise de necessidades formativas aos processos de profissionalização e de formação docentes, a partir do contexto de atuação profissional do professor, é uma possibilidade de estratégia de formação que redimensiona tanto a função quanto a formação de professores, pois, supomos, pode contemplar a complexidade das características específicas do trabalho docente.

Imbernón (2000) define profissionalização como sendo o processo socializador de aquisição de características e capacidades específicas de determinada profissão e afirma que os conceitos atribuídos às profissões não são neutros, são, de outra forma, produtos ideológicos e contextuais, uma vez que "as profissões são legitimadas pelo contexto popular" (IMBERNÓN, 2000, p. 27).

Acreditamos que, no processo de profissionalização docente, combinamse elementos de ordem profissional e formativa, pois a construção do conhecimento profissional docente é um processo contínuo, construído no contexto profissional, durante a formação inicial e a atuação profissional do professor. Esse conhecimento é de natureza complexa, envolvendo a cognição, a experiência e a intuição, num processo direcionado por pressupostos éticos e políticos. 
A especificidade do trabalho docente caracteriza-se, por um lado, por aspectos externos à própria docência, pois é uma profissão situada em um conjunto mais amplo da organização social do trabalho, sendo a sua função bastante direcionada por necessidades, muitas das vezes, não condizentes àquelas próprias do contexto interno da escola. No entanto, por outro lado, é uma profissão que constrói sua identidade específica, de modo fortemente marcante, por meio das relações que estabelece no interior de seu contexto cotidiano.

Pérez Gómez (1995), Tardif e Lessard (2007) e Roldão (2006) discutem como sendo um dos traços específicos da profissão docente as tensões provocadas a partir de uma dupla finalidade existente na educação escolar, distinguida por Pérez Gómez como as funções socializadora e educativa.

Segundo Pérez Gómez (1995), o papel mediador da escola é concomitantemente socializador e educativo (uma complementa a outra) e, por isso, a escola vivencia a constante tensão dessa duplicidade. A função socializadora da escola é responsável por amenizar os efeitos da desigualdade social, sem, contudo, suprimi-la, pois possui potencialidades que garantem aos indivíduos e grupos a possibilidade de se desenvolver intelectual, afetiva e socialmente, promovendo sua inserção social. Já a função educativa amplia e revaloriza a atuação da escola, pois atribui a ela um papel de contraste em relação aos princípios da cultura hegemônica, na medida em que pro- porciona a reconstrução do pensamento dos indivíduos e dos grupos por meio da reflexão. A prática e o desenvolvimento da reflexão, desse modo, são fundamentais para que a escola possa se colocar como uma mediadora da transformação do pensamento humano em contraste ao pensamento socialmente dominante.

Sendo assim, para atender a função educativa da escola, esse autor considera essencial a caracterização do trabalho docente como hermenêuticoreflexivo, uma vez que concebe o ensino como uma atividade complexa, que ocorre em cenários singulares, determinados pelo contexto. $\mathrm{O}$ autor esclarece que o trabalho docente atua em um ambiente psicossocial vivo e em constante transformação, no qual interagem múltiplos fatores e condições. Nesse ambiente, o docente enfrenta problemas imprevisíveis de ordem prática, que requerem opções éticas e políticas e que, portanto, a mera interferência técnica ou a aplicação de uma regra procedimental pré-determinada não contempla a complexidade das situações educativas. Para essa concepção de prática docente, o conhecimento docente é construído na atuação pedagógica, sendo resultado da combinação entre a investigação das situações do ambiente educativo e a utilização dos instrumentos e ferramentas conceituais desenvolvidas pelo professor no decorrer da sua formação intelectual. Portanto, para esse autor, o componente básico da prática docente, aquele que especifica o trabalho docente, é o desenvolvimento da reflexão. 
Para Pérez Gómez (1995), a natureza da profissão docente é artística, porque lida na prática com situações sempre únicas, e é também reflexiva, porque requer a reconstrução constante do pensamento docente sobre sua prática e sobre outros aspectos de ordem ética, política e cultural, originários das situações reais de interação no ambiente escolar.

Tardif e Lessard (2007, p. 31), por sua vez, redimensionam a docência, conceituando-a como um trabalho interativo, porque "ensinar é trabalhar com seres humanos, sobre seres humanos, para seres humanos". Extrapola, pois, os limites da definição dos trabalhos que lidam com a matéria inerte, pois se caracteriza pela própria complexidade do seu objeto de trabalho, ou seja, o ser humano. As interações inerentemente estabelecidas entre o trabalhador e o seu "objeto trabalhado" são dimensionadas por fatores que ultrapassam a dimensão meramente técnica. A reflexão e a interação, portanto, passam a ser componentes essencialmente relevantes para as relações de trabalho que envolvem o ser humano como "objeto de trabalho", pois "as pessoas não são um meio ou uma finalidade do trabalho, mas a 'matéria prima' do processo do trabalho interativo e o desafio primeiro das atividades dos trabalhadores" (TARDIF; LESSARD, 2007 , p. 20). Segundo esses autores, a presença de um outro sujeito na relação com o trabalhador conduz para um novo modelo de relação de trabalho, baseado na interação humana, caso contrário, corre-se o risco de impor ao ser humano uma natureza não própria da sua humanidade, mas manipulada para fins de dominação, repressão e subjugação.

Especificamente a docência, por sua vez, é um trabalho interativo porque a interação com o "objeto humano" está no centro do trabalho do professor. A docência, "enquanto trabalho de interação, apresenta ela mesma alguns traços particulares que estruturam o processo de trabalho cotidiano no interior da organização escolar" (TARDIF; LESSARD, 2007, p. 11). Esses traços distintivos originam-se da própria interação, no contexto escolar, entre os professores e seus alunos e entre os professores e demais agentes escolares.

De modo análogo a Pérez Gómez (1995) e a Tardif e Lessard (2007), Roldão (2006), por sua vez, acrescenta que a definição da função docente é histórico-social e que depende de fatores extrínsecos e intrínsecos à profissão, o que redimensiona a atuação docente, ampliando os limites da mera atuação técnica para uma atuação ética, política e social frente à natureza da docência. É nesse sentido que Roldão (2006, p. 5) defende "a centralidade do conhecimento profissional como factor decisivo da distinção profissional", ou seja, essa autora reconhece a importância da autonomia como componente fundamental na especificidade do profissional docente, na atualidade. Ainda para essa autora, o ato de ensinar é o traço distintivo da profissão docente e essa função específica "já não é hoje definível 
pela simples passagem do saber, não por razões ideológicas, ou apenas por opções pedagógicas, mas por razões sócio-históricas" (ROLDÃO, 2006, p. 2). Roldão (2006) cita como características do conhecimento específico do docente a sua natureza compósita; a capacidade analítica; a natureza mobilizadora e interrogativa; a meta-análise; e por fim, a comunicabilidade e a circulação.

Ao relacionarmos as especificidades do trabalho docente à formação de professores, compreendemos quais características impõem-se como necessárias ao cultivo de uma formação que melhor contemple a complexidade da profissão docente. Nesse sentido, ao conceber o trabalho docente como um trabalho de natureza reflexiva, artística (PÉREZ GOMÉZ, 1995), interativa (TARDIF; LESSARD, 2007) e compósita (ROLDÃO, 2006), concordamos com Imbernón (2000) ao afirmar que a formação de professores deve ser redimensionada para atender as finalidades de superar a mera atualização técnica, possibilitando mais espaços de participação e reflexão do docente; e de estimular a sua criticidade, proporcionando a compreensão das contradições da profissão e das situações que perpetuam a alienação profissional.

Baseados, então, nesse aporte teórico exposto até aqui, entendemos que a formação de professores, capaz de contemplar a complexa natureza da profissão docente e de desenvolver um profissional apto a compreender as contradições próprias do seu trabalho, situa-se no contexto da própria escola e empenha-se em motivar os professores a serem pesquisadores da sua prática e a se envolverem em processos de reflexão e de interação. A escola, desse modo, passa a possuir dupla função também na constituição do seu trabalhador, o professor: a função de profissionalizá-lo e a função de formá-lo permanentemente. A profissionalização e a formação do professor estão ligadas diretamente ao exercício de sua prática profissional e, portanto, podem articular-se entre si no ambiente da prática da docência, ou seja, o contexto escolar.

De acordo com essa perspectiva de formação, que integra a pesquisa, a formação e a profissionalização, a formação legitima-se quando contribui "para o desenvolvimento profissional do professor no âmbito do trabalho e de meIhoria das aprendizagens profissionais" (IMBERNÓN, 2000, p. 45). Isto equivale a dizer que a legitimidade da formação se dá quando as aprendizagens repercutem nos sistemas de trabalho e, estes, por sua vez, na formação. É por esse motivo que acreditamos que o desenvolvimento profissional do professor impulsiona o desenvolvimento institucional da escola.

A formação, portanto, vinculada à profissionalização e à pesquisa a partir do local de trabalho, configura-se numa possibilidade de desenvolvimento da autonomia profissional docente, na medida em que os professores e os futuros professores são motivados a refletirem sobre sua formação e profissionalização de forma articulada, por meio da pesquisa, que é realizada por eles próprios. 
A análise de necessidades docentes, nesse sentido, configura-se como um instrumento capaz de direcionar ações formativas e também em um meio de formar professores no seu ambiente profissional.

2.3 A análise de necessidades formativas e o planejamento de projetos de formação contínua de professores

Segundo Rodrigues e Esteves (1993), a análise de necessidades foi introduzida na área educativa, no final da década de 1960, para auxiliar no planejamento de processos formativos que respondessem mais eficazmente às exigências sociais. Ainda conforme essas autoras, por um lado, a análise de necessidades é entendida como uma técnica e um conjunto de procedimentos e, por outro, também é concebida como etapa do processo pedagógico de formação.

O estudo da análise de necessidades desenvolveu-se e aprofundou-se primeiro no campo da formação de adultos e depois no campo da formação contínua de professores. Vários autores ${ }^{1}$, citados por Rodrigues e Esteves (1993), concordam que a negociação entre os

${ }^{1}$ FERRY, G. Problématiques et pratiques de l'éducation des adultes. Quelques points de repères pour la formation des enseignants. Revue française de Pédagogie, n. 50.

JOBERT, G. Identité professionnelle et formation continue des enseignants, Éducation permanente, n.80.

DOMINICÉ, P.; ROUSSON, M. L'éducation des adults et ses effets. Problématique et etude da cas. Berne: Peter Lang, 1981. agentes envolvidos nos contextos formativos é fundamental para o sucesso das ações formativas para adultos, sejam esses, professores ou outros trabalhadores. O motivo dessa certeza é que quanto mais espaço os profissionais têm para discutir e deliberar sobre a própria formação, mais se envolvem ao longo do processo de formação. Dessa forma, tanto na etapa de determinação das necessidades formativas como nas de formulação e avaliação da ação formativa, a negociação leva o profissional a um envolvimento menos passivo no processo formativo.

Essa posição mais participativa do professor pressupõe situações formativas nas quais este poderá desenvolver faculdades intelectuais e comportamentos profissionais mais próximos de uma abordagem reflexiva sobre as problemáticas educacionais. Durante essas situações de formação, todo o conjunto de seu saber (pessoal, profissional, prático, teórico etc.) é acionado na busca de soluções e propostas para a satisfação das suas necessidades formativas.

Os projetos de formação de professores, segundo Rodrigues e Esteves (1993), podem ser direcionados no atendimento de necessidades levantadas de acordo com as seguintes perspectivas: do sistema, do formador ou do formando. Para essas autoras, dependendo dos objetivos de cada pesquisa realizada, o seu estudo pode evidenciar: os interesses sociais presentes numa dada situação de trabalho, revelando necessidades originárias de um coletivo; as exigências 
do sistema educativo ou as expectativas e necessidades individuais.

Nesse sentido, conforme Rodrigues e Esteves (1993), no âmbito da formação de professores, duas perspectivas dominam a área de análise de necessidades: a de ajustamento entre a "procura" de formação e a "oferta" e a de ajustamento da "oferta" à "procura" de formação. Segundo as autoras, ambas as perspectivas residem no campo pedagógico, pois concebem a participação do docente no processo de levantamento e análise das necessidades, com a finalidade de contribuir para as relações pedagógicas entre formador e formando. A primeira no sentido de diminuir as resistências quanto aos objetivos, conteúdos e às estratégias envolvidos nas ações formativas. A segunda, por sua vez, tem uma finalidade mais formativa, a de garantir ao professor a posição de sujeito da sua formação, incentivandoo a desenvolver-se tanto pessoal como profissionalmente, a partir do processo de planificação das ações formativas.

Tomando por base o que foi exposto, reiteramos que a pesquisa sobre as necessidades formativas configura-se em um importante instrumento para o planejamento de projetos de formação contínua de professores. Tais pesquisas contribuem para levantar dados para a elaboração e avaliação de projetos de formação, além de possibilitarem o envolvimento do professor numa dimensão mais ampla do trabalho docente, pois possibilita ao professor a compreensão da fluência dialética entre o pedagó- gico e o político, uma vez que ele se conscientiza das próprias necessidades formativas diante de seus contextos de atuação profissional.

Nesse sentido, a análise de necessidades formativas é um meio capaz de proporcionar ao professor a constante reconstrução da sua identidade a partir da reflexão do desempenho da sua prática dentro do contexto históricosocial no qual está inserido. $O$ estudo das necessidades formativas, regido por pressupostos teóricos voltados para a concepção do desenvolvimento profissional contínuo, pode vir a contribuir para o planejamento de projetos de formação contínua de professores, nos quais as atitudes reflexiva, crítica e autônoma possam ser colocadas em prática.

\section{Metodologia e desenvolvimento da pesquisa}

Tendo em vista nossos objetivos, realizamos uma pesquisa de caráter quanti-qualitativo cujo instrumento de levantamento das necessidades formativas dos professores foi um questionário composto por quarenta e cinco questões, das quais quatro foram abertas e as demais foram fechadas.

Para apreendermos as necessidades desses professores, partimos do pressuposto de que é importante conhecer as suas condições socioeconômicas, culturais e profissionais, bem como as suas expectativas e percepções a respeito da educação escolar. Isso porque as necessidades formativas têm 
relação com a formação, mas também com as condições de trabalho e com as condições sociais, econômicas e culturais nas quais vivem os docentes. Também são relevantes, para a compreensão das necessidades dos professores, as suas representações sobre os papéis da escola e do professor na sociedade, porque essas representações revelam sobre quais perspectivas esses professores planejam e atuam no seu trabalho ${ }^{2}$.

A aplicação dos questionários foi realizada no mês de dezembro de 2007, para todos os professores das escolas estaduais que possuíam o ciclo I, do Ensino Fundamental, do município de Presidente Prudente, as quais totalizavam onze. Havia, na ocasião, cento e onze professores lecionando em classes regulares de 1a a $4^{\underline{a}}$ séries $^{3}$, dentre os quais dezesseis docentes $(14,41 \%)$ se recusaram a preencher o questionário ou estavam em licença saúde. Foram distribuídos, então, noventa e cinco questionários, dos quais setenta e dois retornaram, correspondendo a uma amostra de, aproximadamente, 76\%. Os dados coletados pelo questionário foram ta-

\footnotetext{
${ }^{2}$ Garcia (1995, p. 65), ao citar estudos realizados por Showers, Joyce e Bennett, declara que dentre as descobertas feitas por esses autores nas suas investigações sobre formação contínua de professores está a conclusão de que "o que o professor pensa sobre o ensino influencia a sua maneira de ensinar, pelo que se torna necessário conhecer as concepções dos professores sobre o ensino".

${ }^{3}$ Não compõem esse número as classes de educação especial, pois são atribuídas a professores com especificações formativas para essa tarefa.
}

bulados com o auxílio do software SPSS ${ }^{4}$ e foram organizados em sete itens, por meio dos quais pudemos analisar as necessidades dos professores pesquisados a partir: do seu perfil socioeconômicocultural; da sua formação profissional; das suas condições de trabalho; das suas expectativas sobre o papel da escola, o trabalho docente e a formação contínua de professores; quanto aos conteúdos das disciplinas de Matemática, Português, Geografia, Ciências e História; a partir das suas demandas em relação a outros conhecimentos escolares; e, por fim, a partir do seu conhecimento sobre documentos e programas educacionais oficiais, explicitadas longamente em Yamashiro (2008).

\section{Resultados da pesquisa}

Pesquisar as necessidades formativas do grupo de professores participantes deste estudo possibilitou-nos formular alguns indicadores para o planejamento de projetos futuros de formação contínua, quais sejam:

1. Devido à natureza reflexiva, artística, interativa e compósita da docência, a formação contínua de professores deve superar os meros modelos de atualização técnica, pelos quais vem sendo concebida;

2. A presença de professores na elaboração, implementação e avaliação de ações formativas favorece a cons-

\footnotetext{
${ }^{4} \mathrm{O}$ software SPSS é um sistema de análise estatística e manuseamento de dados.
} 
trução de projetos educacionais mais próximos da ideologia dos docentes;

3. O ambiente de trabalho do professor constitui-se num espaço de formação e de profissionalização, configurando-se, portanto, como local propício para o desenvolvimento de ações formativas capazes de superar modelos de formação, baseados apenas na racionalidade técnica. Conforme os dados da pesquisa empírica, $39 \%$ dos professores estão de acordo com esta afirmativa, pois apontam como primeira opção a escola como local preferido para a formação contínua, e 17,7\% indicam, como motivação favorável para o êxito das ações formativas, a realização destas no horário de trabalho do professor;

4. A análise de necessidades formativas configura-se, por um lado, em um instrumento eficaz para o levantamento de dados para o planejamento de políticas públicas destinadas à formação contínua de professores. Por outro lado, configura-se em um procedimento formativo quando articulado aos processos de profissionalização e formação do professor;

5. A situação profissional dos docentes favorece ou impede o seu desenvolvimento profissional. Portanto, a articulação entre a situação funcional dos docentes com as suas condições de trabalho e com a sua formação contínua é fundamental para a compreensão das suas necessidades. Dessa forma, diante da situação funcional e das condições de trabalho dos professores participantes desta pesquisa, sugerimos que a formação contínua desses profissionais se realize dentro da sua jornada de trabalho. De acordo com os dados levantados, $37,6 \%$ dos docentes dão aulas em mais de uma escola, dos quais $22,66 \%$ trabalham mais de quarenta horas semanais dentro da sala aula. Já $23,8 \%$ dos docentes apontam como ponto negativo para as ações formativas a sua realização fora da jornada de trabalho do professor e outros $18,8 \%$ dos pesquisados expressam ser desgastantes as ações formativas que possuem carga horária excessiva ou que sobrecarregam os professores com atividades extras;

6. A formação contínua dos professores pesquisados deve assumir o papel de conscientizar os professores em relação aos aspectos associados ao desenvolvimento e exercício da sua própria cidadania, além de conscientizá-los para a importância da formação da cidadania dos seus alunos, já que a pesquisa nos mostrou que a maioria dos professores pesquisados não assume um posicionamento atuante politicamente na sociedade. Cerca de $71 \%$ dos professores não vão a associações de bairro; 47,1 \% não frequentam os seus próprios sindicatos e $80 \%$ nunca foram a nenhum encontro ou reunião de algum partido político;

7. A maioria dos professores pesquisados, 91,5\%, demonstra disposição em investir em prol da continuidade dos seus estudos. No entanto, para que as aprendizagens veiculadas na formação contínua contribuam para o seu desenvolvimento profissional, é importante ter o cuidado de não incentivar políticas que 
valorizem apenas a certificação e a mercantilização de processos formativos;

8. As ações de formação de professores devem levar em consideração as necessidades próprias de cada fase profissional docente. Sendo assim, 41,3\% dos professores pesquisados (trinta e um professores) estão no final da carreira, o que torna relevante considerar as características próprias dessa fase como definidoras para as ações de formação contínua desses professores;

9. As ações formativas destinadas aos professores pesquisados devem auxiliá-los a superar o conflito, demonstrado pela pesquisa, entre as necessidades impostas pelo sistema educacional e as necessidades profissionais dos docentes questionados. Nesse sentido, a análise das dimensões política, cultural, social e ética do ensino dos conteúdos escolares faz-se necessária, além da discussão a propósito das próprias metodologias de ensino, pois proporciona o desenvolvimento da atitude reflexiva e crítica a respeito dos conteúdos disciplinares a serem selecionados para a composição dos currículos. $O$ estudo reflexivo e crítico dos Parâmetros Curriculares Nacionais para as quatro primeiras séries do Ensino Fundamental, bem como das Propostas Curriculares para o ciclo I do Ensino Fundamental do Estado de São Paulo, publicadas em 1986, pode ser o ponto de partida para analisar os conteúdos das disciplinas, uma vez que constatado, por esta pesquisa, que a maioria dos professores conhece regularmente esses documentos, $30,6 \%$ e $73,6 \%$, res- pectivamente. Ressaltamos que discutir e refletir sobre os conteúdos curriculares não significa impor ao professor propostas curriculares prontas, pois a imposição fere o princípio da autonomia docente. De outra forma, é necessário que o ajuste entre as necessidades dos indivíduos (professores e alunos) e do sistema seja possibilitado pelo diálogo e negociação entre os professores, comunidade e representantes de órgãos oficiais educacionais;

10. Os processos de formação contínua devem auxiliar os professores a compreender as suas próprias necessidades formativas para que possam buscar e reivindicar ações de formação contínua que efetivamente contribuam para o seu desenvolvimento profissional. Como demonstrou o levantamento de dados, 29,5\% dos professores expressaram ser importante levar em consideração suas necessidades no planejamento de projetos de formação contínua;

11. Conforme os dados levantados pela pesquisa, $86,9 \%$ dos professores manifestaram não possuir conhecimentos suficientes sobre o FUNDEB e 81,7\% alegaram não conhecer suficientemente o PNE. Desse modo, os projetos de formação contínua, destinados a esse grupo de professores, devem incentivar o estudo, a reflexão e a discussão desses documentos oficiais a fim de embasar teoricamente e motivar esses professores a exercerem um posicionamento crítico em relação aos encaminhamentos direcionados para a educação escolar do município de Presidente Prudente. 


\section{Referências}

GARCIA, Carlos M. A formação de professores: novas perspectivas baseadas na investigação sobre o pensamento do professor. In: NÓVOA, António (Coord.). Os professores e a sua formação. Lisboa: Dom Quixote, 1995. p. 51-76.

IMBERNÓN, Francisco. Formação docente e profissional: formar-se para a mudança e a incerteza. São Paulo: Cortez, 2000.

PÉREZ GÓMEZ, Ángel. Autonomia profesional del docente y control democrático de la práctica educativa. In: CONGRESO INTERNACIONAL DE DIDÁCTICA. Volver a pensar la educacion. Madrid: Morata, 1995. p. 339-353.

RODRIGUES, Ângela; ESTEVES, Manuela; $A$ análise de necessidades na formação de professores. Porto: Porto, 1993.

ROLDÃO, Maria do Céu. Função docente: natureza e construção do conhecimento profissional. Cadernos da Anped, Caxambu, 2006.

SINGER, Paul. Poder, política e educação. Revista Brasileira de Educação, [S.I.], n. 1, p. 5-15, jan./fev./mar./abr. 1996.

TARDIF, Maurice; LESSARD, Claude. O trabalho docente hoje: elementos para um quadro de análise. In: . O trabalho docente: elementos para uma teoria da docência como profissão de interações humanas. Petrópolis: Vozes, 2007. p.15-54.

TEDESCO, Juan Carlos. O novo Pacto Educativo. São Paulo: Ática, 2004. 150 p.

YAMASHIRO, Carla R. C. Necessidades formativas dos professores do ciclo I do Ensino Fundamental de Presidente Prudente - SP. 2008. 176f. Dissertação (Mestrado em Educação) - Universidade Estadual Paulista, Presidente Prudente, 2008.

\section{Recebido em agosto de 2013}

Aprovado para publicação em dezembro de 2013 